\title{
Do contrato sexual ao reconhecimento: repensando a prostituição por um olhar teórico-crítico
}

\author{
From the sexual contract to recognition: rethinking \\ prostitution through a critical-theoretical view
}

\section{Tarine Guima Gonçalves $\left.{ }^{\mathrm{a}}{ }^{(}\right)$e Thaís de Almeida Lamas ${ }^{\mathrm{b}}$ ()}

\begin{abstract}
Resumo A partir de um breve panorama das críticas do socialismo clássico à prostituição, discutindo a pauta "abolicionista", propomos uma forma, entre as várias possíveis, de dar continuidade a esses argumentos no âmbito da teoria política contemporânea. $\mathrm{O}$ que fazemos é colocar duas autoras socialistas, a princípio dissidentes, em diálogo para analisar o fenômeno da prostituição: 1. Apresentamos a concepção de Carole Pateman sobre a prostituição. 2. Acatamos a crítica de Nancy Fraser ao modelo de Pateman, e utilizamos sua própria teoria crítica da justiça para analisar a questão da prostituição, explorando possíveis aproximações e distanciamentos entre ambas. 3. Apontamos para um possível caminho de se "ler" a prostituição, pelas chaves dos critérios de justiça do reconhecimento e da redistribuição. 4. Buscamos, em suma, reivindicar o papel da teoria política em discutir temas caros ao feminismo, como o da prostituição, tentando contribuir com a abertura e a continuidade dessas discussões nessa área disciplinar.
\end{abstract}

Palavras-chave Contrato sexual. Prostituição. Justiça. Reconhecimento. Redistribuição.

\begin{abstract}
Starting off from a brief horizon on the critique from the classical socialism on prostitution, discussing the "abolitionist" agenda, we propose one way (within the various possible ways) to give the continuity to these arguments on the grounds of contemporary political theory. We shall put two socialist authors in debate (although they initially dissent), in order to analyze the prostitution phenomenon: 1. We present Carole Pateman's conception on prostitution. 2. We agree with Nancy Fraser's critique on Pateman's model, and we utilize Fraser's own critical theory of justice to analyze the prostitution issue, exploring the possible approximations and distances between both authors. 3. We aim to a possible way in "reading" prostitution, through the justice
\end{abstract}

a Mestranda em Ciência Política pela Universidade de São Paulo (FFLCH-USP) e membra do DesJus - Seminários em Desigualdades e Injustiças/CEBRAP.

b Mestra em Ciências Sociais pela Universidade Federal de São Paulo (EFLCH-Unifesp) e graduada em Biblioteconomia pela Universidade Federal do Rio de Janeiro (UFRJ). 
criterions of recognition and redistribution. 4. We tend to reinvidicate the political theory's role on discussing themes that are akin to feminism, such as the prostitution one, trying to contribute with the widening and the continuity of these discussions within this disciplinar area.

Keywords Sexual contract. Prostitution. Justice. Recognition. Redistribution.

\section{INTRODUÇÃO}

O tema da prostituição [...] esteve no raio dos quadros interpretativos da política desde, pelo menos, o século XVIII. Essa presença não decorre do fato de a prostituição ser [...] a profissão mais antiga do mundo, mas por ela ser considerada uma das instituições que revela as relações de poder entre homens e mulheres e a moral sexual de cada período histórico (Paradis, 2018, p. 1).

A partir de tais afirmações, Paradis $(2017,2018)$ nos traz alguns exemplos de como a questão da prostituição é tratada em tradições do pensamento político e, especificamente, dentro do socialismo e do marxismo, como questão catalisadora de problemas cruciais acerca da desigualdade de gênero e da emancipação da mulher na sociedade. Para introduzir o debate que se pretende fazer aqui, reconstruiremos alguns desses exemplos nesta introdução. Porém, nosso foco não está somente em pensar a questão da prostituição a partir das pensadoras socialistas e marxistas, senão repensá-la de um ponto de vista reformulado e atento à contemporaneidade, com o auxílio da teoria crítica (Fraser, 1985, 1993, 2006, 2007). O faremos sem descartar as potencialidades da importante crítica socialista à prostituição e da noção de patriarcado (Pateman, 2020 [1988], 1999), sem a qual não conseguiríamos suscitar um olhar que é crítico à instituição da prostituição. É importante ressaltar, sobretudo, que pretendemos construir uma discussão nos moldes da teoria política normativa e da teoria crítica. Ou seja: uma discussão sobretudo teórica, que olha para significações e conceitos do que é estrutural no imaginário político ${ }^{1}$, e que não necessariamente tem como foco mapear uma historiografia estrita acerca do fenômeno da prostituição, tampouco análises que contemplem com maior vigor a experiência empírica² ${ }^{2}$ tarefas que

1 Para discussões acerca das atribuições da teoria política feminista normativa, ver Biroli, 2017.

2 Importantes trabalhos têm sido realizados nesses âmbitos, sobretudo para pensar a realidade empírica brasileira ao investigar a história do movimento organizado de prostitutas no país (Bonomi, 2019), ou ao ouvir o que as prostitutas de rua têm a dizer sobre os projetos brasileiros de regulamentação (Afonso, 2014). 
são de muita importância para a análise da prostituição como um todo, mas que não estão ao nosso alcance no presente artigo.

Porém, é importante ressaltar que, ao falar sobre prostituição, não falamos sobre um fenômeno social fixo, senão sobre uma prática detentora de múltiplas noções, entendimentos e formatos que se alteram ao longo da história ${ }^{3}$. Adiantamos que, para os propósitos deste artigo, estamos pensando na noção contemporânea da prostituição de mulheres (tanto cisgênero quanto transexuais), que ocorre dentro de contextos consensuais e entre adultos, nas sociedades ocidentais democráticas. Apresentaremos um panorama geral dos argumentos socialistas do séc. XIX como ponta pé inicial ao debate abolicionista, indicando como seus argumentos podem ser resgatados à realidade social contemporânea de que pretendemos falar. Sabemos, no entanto, das inúmeras disputas ainda correntes sobre os significados dados ao fenômeno, mesmo na contemporaneidade. No Dicionário Crítico do Feminismo (2009), tanta é a discordância para uma definição acerca da prostituição, que estão listados dois verbetes diferentes para defini-la: primeiro, Claudine Legardinier diz que, "longe de se limitar à pessoa que troca serviços sexuais por remuneração, a prostituição é, antes de tudo, uma organização lucrativa, nacional e internacional de exploração sexual do outro", e que a análise feminista "considera a prostituição a situação mais extrema da relação de poder entre as categorias de sexo", em que as mulheres são "coisificadas em prol da sexualidade irresponsável dos homens" (Legardinier apud Hirata et al, 2009, p. 198). Na segunda definição, Gail Pheterson diz que a prostituição pode ser simplesmente "a troca de serviços sexuais por uma compensação financeira ou material”, em tom menos crítico à instituição (Pheterson apud Hirata et al, 2009, p. 203).

Num breve panorama da discussão do socialismo clássico, atentamos à consolidação do capitalismo industrial, a moral sexual puritana e as desigualdades entre homens e mulheres, em que se consolida o perfil da massa de prostitutas, advindas da classe trabalhadora e marginalizadas pela sociedade. Nisso, discursos a favor do controle e a normatização da prática são questionados por atores políticos, como por movimentos de mulheres no período, como é o caso dos/as socialistas, no âmbito do marxismo clássico (ainda que não sejam os únicos, já que anarquistas e movimentos eclesiásticos também foram importantes atores na crítica à prostituição), que vêm a criticar a prostituição como atrelada às instituições burguesas e resultante das implicações do sistema capitalista. Nessa forma de crítica, a

3 Para uma análise histórica (e crítica) sobre como o movimento abolicionista se desenvolveu, sobretudo ao longo da história europeia, ver Walkowitz, 1980. Para exemplos históricos da realidade brasileira ver Rago, 1990. 
prostituição não é encarada de forma puritana, mas suscitam-se concepções sobre opressão de gênero e autonomia sexual, a partir das perspectivas contrárias às desigualdades perpetuadas pelo capitalismo (Paradis, 2018, p. 2-3).

Isto é, encontra-se, desde seus primórdios, fortes críticas à prostituição, tanto no socialismo utópico, quanto no marxismo, onde a prostituição é vista não como uma "degradação estritamente moral da sociedade, mas como espaço das contradições que o capitalismo e a moral burguesa impunham sobre as relações entre homens e mulheres" (Paradis, 2018, p. 3). Paradis nos traz o exemplo da socialista utópica Flora Tristan, que era forte defensora da abolição das causas da prostituição, e não de sua regulamentação, dizendo que "até que a emancipação da mulher tenha lugar, a prostituição vai crescer todos os dias" (Tristan, 2009, p. 61 apud Paradis, 2018, p. 6). Já para a bolchevique Alexandra Kollontai, não bastaria o fim do capitalismo para acabar com a opressão das mulheres: seriam necessárias a politização e a revolução da vida privada. A autora aborda a questão da prostituição a partir de sua influência na psicologia humana, na medida em que ela deformaria as relações sexuais, partindo da visão de que a sexualidade seria uma forma elevada de enriquecimento pessoal, de sentimentos elevados que devem estar fora de relações mercantis (Kollontai, 2007 apud Paradis, 2018, p. 13).

Vê-se, a exemplo das autoras mencionadas, que as teorias do socialismo foram vozes importantes para uma análise crítica à prostituição, do séc. XIX ao séc. XX, sendo enxergada como "uma instituição fundamental para manutenção da hipócrita moral burguesa e para a manutenção das desigualdades de gênero e classe" (Paradis, 2018, p. 16), no tocante de que, para as autoras mencionadas, ela é considerada uma instituição política (Paradis, 2018, p. 17). Porém, é possível notar as limitações das abordagens marxistas do feminismo, já que se desconsidera a questão do patriarcado e, ainda, nas visões ortodoxas, relegava-se demandas feministas para segundo plano, alegando que o fim da opressão das mulheres se daria simplesmente com a derrubada do sistema capitalista (Paradis, 2018, p. 17).

No entanto, a partir da segunda metade do séc. XX, as críticas socialistas à prostituição, tal como descritas aqui, decaem e emergem as reivindicações de que a prostituição seria um trabalho "comum" (não descartando suas particularidades), e não uma forma direta de violência em si mesma, pautando sua regulamentação como saída para acabar com estigmas da profissão4. Para Paradis, devemos afunilar

4 Não se trata, no entanto, de dizer que a prostituição seria um trabalho "como outro qualquer". As autoras que defendem argumentos próximos à regulamentação procuram apresentar as particularidades inscritas na prática da prostituição, como evidenciar o perfil majoritário de pessoas na "profissão", sendo pessoas racializadas, marginalizadas etc. Mas, é evidente que, de 
a relação entre igualdade, liberdade, autonomia e reconhecimento, a fim de construir diálogos para repensar a prostituição "como uma instituição que ainda hoje regula as relações de gênero, classe e raça” (Paradis, 2018, p. 18).

Aqui, tomaremos essa tarefa como nossa, retomando o debate sobre a prostituição por via de uma análise crítica, tal como fizeram as autoras socialistas, pensando alternativas de análise a partir de seus diagnósticos, mas trazendo-os para o diálogo da contemporaneidade. Para tanto, utilizaremos como ponto de partida a teoria da autora socialista contemporânea Carole Pateman (1988), que teoriza sobre o contrato sexual e constrói sua noção de patriarcado, dentro dos quais a prostituição estaria inserida. Porém, notamos que o diagnóstico de Pateman não esgota as possibilidades de crítica e, segundo Nancy Fraser (1993), sua teoria teria certas lacunas a serem preenchidas para se aproximar da realidade social contemporânea. Tomaremos a crítica de Fraser como válida e utilizaremos da própria teoria crítica da autora para atribuir novos alcances analíticos para se repensar a questão da prostituição. Fraser apresenta uma teoria crítica da justiça, que é sensível a questões de gênero e da teoria feminista, enfatizando sua gramática dual que abarca injustiças de redistribuição e reconhecimento em análises que visam a emancipação de minorias diante de ambos os cenários econômicos e culturais, trazendo concretude aos diagnósticos e prognósticos teóricos de nosso tempo.

\section{CONTRATO E PROSTITUIÇÃO}

Pateman reinterpreta as teorias clássicas do contrato social, inserindo nele a categoria sexual ${ }^{5}$, em que, de modo geral, os consentimentos voluntários de acordo mútuo seriam na verdade produtores de padrões de submissão, sobretudo de mulheres a homens. Para Pateman, já em análises anteriores (1970, 1979) ao Contrato Sexual (2020 [1988]) ${ }^{6}$, a democracia liberal seria um limite à autonomia, sendo calcada nesse tipo de contrato (Miguel, 2017, p. 2-3). Dominação e explo-

saída, as autoras regulamentaristas reivindicam a prostituição como uma "profissão" ou um

"trabalho", longe de questioná-la enquanto tal. Isto é, listam-se as precariedades da "profissão" da prostituição, assim como pode-se listar as precariedades da profissão de operário, por exemplo, sem que nos questionemos se realmente se trata de uma profissão e o que seria uma concepção adequada de profissão. Para trabalhos que explorem essas questões, ver: Nussbaum, 1999; Kempadoo, 2001; Piscitelli, 2012; Shrage, 2016.

5 Pateman não utiliza a categoria "gênero" para falar sobre as especificidades sociais da feminilidade e da masculinidade, mas coloca em sua análise a categoria do "sexo" propriamente dito. Para um debate acerca das diferenciações e desenvolvimentos entre sexo e gênero, sobretudo ao pensar a questão das mulheres, ver Nicholson, 1994.

6 É importante ressaltar que o Contrato Sexual (1988) foi escrito em meio ao contexto das "Sex Wars” do feminismo, sobretudo em que posicionamentos pró-sexo ou contra a utilização da sexualidade como forma de emancipação feminina estavam em disputa, consequentemente abarcando o dilema acerca da regulamentação ou não da prostituição. Para críticas à concepção de Pateman da prostituição, ver Overall, 1992. E, para uma contextualização das Sex Wars 
ração se tornam uma cooperação interindividual, em que os sujeitos são postos de forma voluntária em relações de obediência, na medida em que transacionam suas liberdades, alienando direitos individuais (Miguel, 2017, p. 2-3). Mais especificamente, trata-se sobre a gênese do direito político enquanto um direito patriarcal, calcado em relações sedimentadas por gênero, como forma do poder que os homens exercem sobre as mulheres (Pateman, 2020, p. 13-14). Para ela, a ordem patriarcal não trata mais do direito paterno, sendo ele apenas uma das dimensões do direito patriarcal. Na sociedade civil moderna, as mulheres estão subordinadas aos homens enquanto homens, num modo de fraternidade (Pateman, 2020, p. 16).

O problema da subordinação está presente nas diversas manifestações de contrato, como o contrato de trabalho e o de casamento. Tal discussão é acessada por via da crítica socialista ao contrato, em que mecanismos de exploração são vistos como moldados como relações contratuais espontâneas. Além da exploração, a questão da subordinação também se faz presente, tanto nos contratos de trabalho, quanto de casamento. Trata-se, então, de um ordenamento social em que estão garantidas a igualdade entre os homens, de forma coletiva, e a submissão das mulheres (Miguel, 2017, p. 8). E, para Pateman, o exemplo mais dramático da dimensão pública do direito patriarcal "é o fato de os homens exigirem que o corpo das mulheres esteja à venda como mercadoria no mercado capitalista; a prostituição é uma importante indústria capitalista” (Pateman, 2020, p. 33).

É importante pontuar que, para Pateman, a prostituição seria uma instituição generificada, já que "a prostituta” é convencionalmente figurada como uma mulher, e elas seriam, de fato, a grande maioria inserida na prática - e os clientes, por sua vez, homens (Pateman, 1999, p. 55). Isso contradiz o argumento que considera a prostituição como o mero contrato entre dois indivíduos descorporificados e livres de identidade. Pateman também nega a afirmação de teor contratualista de que feministas contrárias à prostituição estariam denotando problemas às mulheres inseridas na prática: ora, quando socialistas criticam o capitalismo, não estão indo contra os trabalhadores, mas sim contra esse determinado sistema. A afirmação patriarcal de que a prostituição seria um problema sobre as mulheres certifica o fato de que o "outro" participante no contrato da prostituição escapa do escrutínio de juízo. Pela história do contrato sexual, a prostituição pode ser vista como um problema sobre os homens. Isto é, o problema da prostituição é catalisado na questão do porquê homens demandam que os corpos das mulheres estejam

dentro do movimento e da teoria feminista, ver Showden, 2016. Para uma abordagem focada especialmente na teoria política, ver Brown, 1987. 
à venda como mercadoria no sistema capitalista: para a autora, a prostituição é parte do exercício da lei do direito do sexo masculino, que seria o modo pelo qual os homens têm garantia de acesso aos corpos das mulheres (Pateman, 1999, p. 56).

Ao falar sobre a comparação da prostituição com outros tipos de trabalho, Pateman denota que, a propriedade de si, não pode ser provida sem a presença integral dessa mesma pessoa que, ao contrário da propriedade material, não pode ser separada de seu dono. Se a propriedade de si de um indivíduo é separada dele, há similaridade com a escravidão, já que os corpos seriam sujeitos do contrato à venda. Portanto, ao se comparar o contrato da prostituição com a venda da força de trabalho, diz-se que "nenhuma forma de força de trabalho pode se separar do corpo, mas só no contrato da prostituição o comprador obtém direito unilateral de uso sexual direto do corpo de uma mulher" (Pateman, 1999, p. 58, tradução própria).

Existe, então, uma relação integral entre o corpo e o self neste caso. Pateman diz que eles não seriam idênticos, mas que os selves seriam inseparáveis do corpo. A ideia de propriedade de si, portanto, salienta a importância e o papel do corpo nas relações sociais, isto é, senhores fazem contratos por serviços de indivíduos subordinados a partir de um self corporizado e, consequentemente, diferenciado sexualmente e generificado. Já que masculinidade e feminilidade seriam identidades sexuais (ou de gênero, num debate amplo), elas são inseparáveis da construção do self. Ou seja, no âmbito do patriarcado moderno, a venda dos corpos das mulheres no mercado capitalista envolve a venda do self de uma maneira diferente, diz Pateman, que seria diferente, por exemplo, da venda do corpo de um jogador de baseball (Pateman, 1999, p. 60).

Para ela, é o ato sexual que provém o sentido do direito patriarcal, na medida em que os corpos das mulheres estejam à venda no mercado capitalista, são os termos do contrato original que estão em voga, e a lei do direito sexual masculino é publicamente afirmada, fazendo com que os homens ganhem reconhecimento público como senhores sexuais das mulheres. Isso é o que há de errado com a prostituição: "a questão crucial, que é muito raramente questionada, é por que há uma demanda global tão grande, por parte dos homens, para que os corpos das mulheres estejam disponíveis à compra como qualquer outro produto do mercado?” (Pateman, 1999, p. 63).

\section{A TEORIA CRÍTICA DE FRASER}

Fraser (1993), em sua crítica a Pateman, aborda a questão da relação entre "senhor e súdita" que é ilustrada pela teórica do contrato sexual. A autora indaga se esse modelo de relação seria adequado para analisar as desigualdades de gênero nas 
sociedades capitalistas contemporâneas e se, por exemplo, as noções de domínio e sujeição esgotariam todos os significados de masculinidade e feminilidade (Fraser, 1993, p. 174). Seu objetivo não é, no entanto, defender o contrato convencional como emancipatório, mas abrir espaço para novas nuances para pensar alternativas às maneiras contemporâneas de dominação.

Tomando o contrato do casamento como exemplo, Fraser diz que, se ele muitas vezes reflete a relação de senhor e súdita, é por conta da sua penetração social em relação aos mercados de trabalho segmentados sexualmente, por regimes com políticas de bem-estar social estruturadas por gênero, ou pela divisão sexual do trabalho doméstico não remunerado (Fraser, 1993, p. 175). Há, então, uma forma diferente e um tanto mais abstrata de mediação e estrutura social, fora do modelo senhor/súdita. Para Fraser, esse modelo teria um foco descontextualizado, que seria limitado para se elaborar uma crítica adequada. E, ainda, o modelo não dá conta do caráter não democrático de um ordenamento social em que muitas das mais importantes questões sociais e políticas estão fora do espaço público coletivo de deliberação e são decididas por meio dos mecanismos do mercado (Fraser, 1993, p. 178). Fraser considera o contrato sexual um modelo insuficientemente estrutural para analisar relações de poder institucionalizadas e lidar com a desigualdade de gênero em sociedades do capitalismo.

Sobre a questão da prostituição, Fraser diz que o modelo de senhor/súdita não se enquadraria, pois o contexto contemporâneo é outro: segundo as palavras da autora (Fraser, 1993, p. 179), as transações têm sido controladas pelas próprias prostitutas; ela menciona que há etnografias que mostram que as prostitutas que seriam de alto escalão (que não configuram a totalidade das prostitutas, sendo apenas uma dentre as múltiplas formas de exercício da prática) têm autonomia e poder considerável nas transações, tirando o protagonismo do cafetão em diversos cenários. E ainda diz que, em algumas culturas masculinas, voltar-se à prostituição como alternativa não seria um símbolo de poder, mas de vergonha, por simplesmente ter de pagar para ter uma relação sexual. Porém, Fraser alega que ela mesma não acredita que a prostituição seja libertadora para as mulheres.

[...] a dominação masculina pode persistir mesmo na ausência de relações de senhores/súditas. Colocando de outra forma, se a mercantilização dos corpos das mulheres não traz igualdade de gênero, a razão não é porque mulheres que assumem a instância de indivíduos possessivos necessitam acatar ordens de superiores masculinos. É, pelo contrário, porque a prostituição codifica signifi- 
cados que são danosos para as mulheres enquanto classe (Fraser, 1993, p. 179, tradução própria).

Ao tomar o contrato sexual como um modelo para apreender significados culturais, Fraser diz que a empreitada funcionaria - ao contrário do caso da análise que Pateman faz da prostituição. Mas a autora denota que Pateman estaria certa ao entender a prostituição contemporânea de um modo "generificado", isto é, trata-se de uma esmagadora maioria de homens comprando sexo de mulheres, numa relação em que o comprador pertence a um status mais alto de gênero do que quem vende, e o serviço vendido é, na maioria das vezes, associado à masculinidade, na dinâmica de domínio sexual e da feminilidade calcada em sujeição sexual (Fraser, 1993, p. 179). Em sua crítica, de modo geral, Fraser diz que os significados contemporâneos de masculinidade e feminilidade teriam, sim, associações com o modelo senhor/súdita, ou com domínio/sujeição. Mas, para ela, a abordagem de Pateman é que seria muito "absolutista", não fazendo jus à complexidade intrínseca desse tipo de relação. Isto é, domínio e sujeição não esgotam todos os significados de masculinidade e feminilidade, estando esses termos à mercê de mudanças históricas e à contestação cultural (Fraser, 1993, p. 180). O que seria, então, uma forma adequada de teorizar a desigualdade de gênero e relações institucionalizadas de poder para Fraser?

Vamos rumar para a teoria crítica da sociedade, e explicar porquê, segundo a definição de Fraser, ela seria uma forma adequada de análise da contemporaneidade. Para a autora (1985, p. 97), ninguém ainda melhor definiu a função da teoria crítica do que Marx em 1843 como "o auto esclarecimento das lutas e desejos da época”. Segundo ela, uma teoria crítica da sociedade conceberia seu aparato conceitual, bem como o enquadramento de seu objeto, sempre olhando para as reivindicações e mobilizações políticas opostas à ordem dominante, com as quais teria uma certa identificação, mas não totalmente livre de críticas. As questões dessa teoria seriam, portanto, informadas e estruturadas pelos interesses dessa identificação (Fraser, 1985, p. 97). O que se exige de uma teoria crítica é, então, o quão bem ela teoriza, neste caso, a situação do movimento feminista e suas reivindicações. E, ao contrário de algumas teorias que ignoram as questões de gênero estruturais para se incomodar apenas com o capitalismo de bem-estar, há que se colocar o problema da dominação e subordinação em primeiro plano (Fraser, 1985, p. 131). Essa seria uma ambivalência que, mais tarde, desencadeia a teoria de Fraser acerca da redistribuição econômica e do reconhecimento cultural, que configuram uma forma de justiça social nas sociedades democráticas contemporâneas. 
Fraser chama atenção para os conflitos chamados "pós-socialistas", em que as demandas políticas, a partir do final do século XX, estão em disputa, dividindo-se entre as questões das identidades de grupo, que suplantam o interesse de classe como meio principal da mobilização política; e a dominação cultural, que suplanta a exploração como forma fundamental de injustiça. Nisso, o reconhecimento cultural substituiria a redistribuição socioeconômica como remédio para injustiça e como objetivo das lutas políticas (Fraser, 2006, p. 231). A questão é, então, compreender tal "virada" do imaginário político. Para ela, existe uma nova tarefa intelectual e prática de desenvolver uma teoria crítica do reconhecimento que "identifique e assuma a defesa somente daquelas versões da política cultural da diferença que possam ser combinadas coerentemente com a política social da igualdade" (Fraser, 2006, p. 231). E, ainda, a autora se preocupa em teorizar sobre os meios pelos quais a privação econômica e o desrespeito cultural se entrelaçariam e se sustentariam de forma simultânea, de modo a esclarecer os dilemas políticos emergentes enquanto se tenta combater as duas formas de injustiça. Seu objetivo maior é ligar essas duas problemáticas políticas, que estariam dissociadas, já que é somente integrando reconhecimento e redistribuição que podemos chegar a um quadro conceitual, diz ela, adequado às demandas de nossa época (Fraser, 2006, p. 232).

Entende-se a injustiça, primeiramente, como socioeconômica. Depois, como cultural ou simbólica, forjada pelos padrões sociais da representação, por exemplo, por meio da dominação cultural e do desrespeito, e outras formas de subordinação. Para Fraser, é preciso distingui-las analiticamente para apreender seu entrelaçamento, a exemplo dos remédios atribuídos a cada uma dessas formas de injustiça. O remédio para a injustiça econômica se dá pela reestruturação político-econômica, como a redistribuição de renda. A injustiça cultural, por sua vez, tem seu remédio voltado para as mudanças culturais e simbólicas, como a revalorização de identidades e o reconhecimento da diversidade cultural. Mais radicalmente, pode-se envolver transformações mais abrangentes dos padrões sociais de representação, bem como o sentido do "eu" de todas as pessoas envolvidas (Fraser, 2006, p. 232).

Neste sentido, Fraser empenha-se em resolver o dilema entre redistribuição e reconhecimento, isto é, a situação na qual pessoas sujeitas à injustiça cultural e à injustiça econômica necessitam de ambos os remédios - que até então estariam em tensão, na medida em que o reconhecimento demandaria afirmar a especificidade do grupo social desse indivíduo, e a redistribuição, por sua vez, aboli-la. Quando se lida com coletividades próximas ao tipo ideal da classe trabalhadora explorada, há injustiças distributivas que demandam remédios distributivos; quando se lida com coletividades próximas ao tipo ideal da sexualidade desprezada, por exemplo, há 
injustiças de discriminação negativa que demandam remédios de reconhecimento positivo. No primeiro caso, o remédio seria ofuscar a especificidade que configura a situação de injustiça a determinado grupo; no segundo, evidenciar e reconhecer positivamente sua especificidade. E há coletividades que estão localizadas em uma região intermediária do espectro conceitual, isto é, são tipos híbridos que combinam, por exemplo, características da classe trabalhadora explorada com a sexualidade desprezada: são as coletividades bivalentes (Fraser, 2006, p. 233).

A diferenciação dessa coletividade vem tanto da estrutura político-econômica quanto da estrutura cultural-valorativa da sociedade, sofrendo injustiças voltadas de forma simultânea à economia política e à cultura, isto é, má distribuição econômica e desconsideração cultural. Porém, nenhuma dessas injustiças seria um efeito indireto da outra, sendo elas primárias e co-originais, fazendo-se necessária a demanda por ambos os remédios, de forma associada: redistribuição e reconhecimento (Fraser, 2006, p. 233). Para ilustrar, Fraser traz os exemplos de gênero e raça, que são paradigmas de coletividades bivalentes, isto é, abarcam dimensões econômicas e cultural-valorativas, demandando tanto redistribuição quanto reconhecimento. Gênero, por exemplo, tem dimensões político-econômicas, pois seria um princípio estruturante básico da economia política, na medida em que estrutura a divisão entre trabalho produtivo remunerado e trabalho reprodutivo doméstico não remunerado, cuja responsabilidade é atribuída à mulher. Mas não bastaria, no caso, abolir a especificidade do gênero. Isto é, não se trata apenas de uma diferenciação político-econômica, mas também de valoração cultural, ou seja, de reconhecimento.

Fraser tem como objetivo diferenciar dois tipos de abordagem de remédios para corrigir a injustiça, que atravessam o divisor entre redistribuição e reconhecimento, chamando-os de "afirmação" e "transformação". Isto é, remédios afirmativos à injustiça são voltados a corrigir os efeitos desiguais de arranjos sociais sem que se abale a estrutura que os forja. E, os remédios transformativos, por sua vez, são voltados a corrigir resultados desiguais por meio da transformação da estrutura subjacente (Fraser, 2006, p. 237). No âmbito do reconhecimento, remédios afirmativos estariam associados ao multiculturalismo mainstream, que propõe compensar o desrespeito cultural por via da revalorização das identidades de grupo, mas sem que se mexa nos conteúdos dessas identidades e nas diferenciações de grupo que são subjacentes a elas. Os remédios transformativos, do contrário, estão associados à desconstrução das estruturas, isto é, compensam o desrespeito cultural por via da transformação da estrutura cultural-valorativa subjacente. Dessa forma, desestabilizam-se as identidades e diferenciações de grupo que refletem as injustiças, não somente elevando a autoestima dos membros 
dos grupos, conforme diz Fraser, mas transformando o sentido do "eu" de todos os envolvidos (Fraser, 2006, p. 237).

Tais distinções também valem para os remédios de redistribuição: os remédios afirmativos, nesse âmbito, estariam associados historicamente ao Estado de bem-estar liberal, que busca compensar a má distribuição terminal, mas sem modificar a estrutura político-econômica subjacente a ela. Remédios transformativos, por sua vez, estão associados historicamente ao socialismo, compensando a distribuição injusta pela transformação da estrutura político-econômica existente, alterando não somente a distribuição das partes de consumo, mas também a divisão social do trabalho e, consequentemente, as condições de existência de todas as pessoas envolvidas. E, ainda, Fraser atenta ao fato de que a redistribuição afirmativa pode estigmatizar pessoas desprivilegiadas, enquanto a transformativa promove a solidariedade, compensando algumas formas de não reconhecimento (Fraser, 2006, p. 238).

Fraser levanta uma questão: sobre os grupos submetidos aos dois tipos de injustiça, então, qual seria a combinação de remédios que melhor funcionaria para minimizar as interferências mútuas que existem entre redistribuição e reconhecimento quando combinados? (Fraser, 2006, p. 239). É aí, então, que a autora elabora o que chama de um "conceito amplo de justiça", capaz de acomodar as reivindicações defensáveis por redistribuição material e por reconhecimento da diferença, de modo simultâneo (Fraser, 2007a, p. 103). Para que isso seja possível, há uma tensão para se desvencilhar: convencionalmente, teóricos tratam a questão do reconhecimento como inerente à ética hegeliana, isto é, a concepções de "boa vida", seguindo condições qualitativas do desenvolvimento humano. E, a redistribuição, por sua vez, estaria ao lado da moralidade kantiana, calcada pelo certo ao invés do bom, ou seja, pela justiça. O que Fraser reivindica em sua teoria é que o remédio do reconhecimento também pode ser alinhado à moralidade, juntamente da redistribuição, sendo também uma reivindicação por justiça - e não de boa vida, de modo que possa ser justificada e aceita por diferentes perspectivas valorativas (Fraser, 2007a, p. 103-05).

Para conceber seu conceito amplo de justiça, Fraser rompe com o modelo padrão de reconhecimento, que é o da identidade, que exige reconhecimento da identidade cultural específica de um grupo. Nele, o não reconhecimento se configura pela depreciação dessa identidade, gerando um dano à subjetividade psíquica dos membros do grupo afetado. Isto é, trata-se de uma política de identidade, em que a estrutura psíquica seria protagonista, em detrimento das implicações das instituições e interações sociais subjacentes, que são os reais motivos de injustiça (Fraser, 2007b, p. 106). Ao contrário, então, sua proposta é tratar do reconheci- 
mento como uma questão de status social: um modelo em que o que se exige do reconhecimento não seria a identidade específica de grupo, mas a condição dos membros de participarem como parceiros integrais na interação social. Neste caso, o não reconhecimento significa subordinação social, e não depreciação da identidade de grupo, ou seja, reparar a injustiça requer uma política de reconhecimento, e não de identidade.

Quando não há reconhecimento, os padrões institucionalizados de valoração cultural designam alguns atores como inferiores, excluindo-os, sendo menos do que parceiros integrais na interação social. Nisso, há não reconhecimento e subordinação de status. Ou seja, no modelo de status, o não reconhecimento se mostra quando as instituições concebem a interação social a partir de normas culturais que impedem a paridade de participação. Isto é, algumas categorias de atores sociais são consideradas normativas e outras como inferiores, por exemplo: brancos ou negros, hetero ou homo, homens ou mulheres, entre outras. Nesses casos, as reivindicações por reconhecimento demandam desinstitucionalizar padrões de valoração cultural que impedem a paridade de participação, substituindo-os por padrões que a promovam. E, dessa forma, a força normativa das reivindicações por reconhecimento, no modelo de status, livra-se da dependência direta a um horizonte de valor substantivo específico, priorizando o correto ao invés do bom. Ou seja, está alinhado à moralidade (Fraser, 2007b, p. 108-10).

Tal abordagem permite importantes vantagens, por exemplo, o fato de se recorrer a um padrão deontológico e não sectário, permitindo que se justifiquem reivindicações por reconhecimento como moralmente vinculantes sob as condições modernas de pluralismo valorativo. Assim, o modelo de status não apela para concepções de boa vida, senão por uma concepção de justiça que deve ser aceita por todos que tenham concepções divergentes da boa vida. Isso torna o não reconhecimento como moralmente inaceitável, já que nega a alguns indivíduos e grupos a possibilidade de participar como iguais na interação social - ou seja, segundo a norma da paridade participativa, que não é sectária e justifica reivindicações por reconhecimento "como normativamente vinculantes para todos aqueles que concordam em seguir os termos justos da interação, sob as condições de pluralismo valorativo" (Fraser, 2007, p. 113). E, além disso, ao conceber o não reconhecimento como subordinação de status, localiza-se os equívocos nas relações sociais, e não na psicologia individual ou interpessoal, fazendo com que a não paridade de participação seja moralmente indefensável, para além de distorcer ou não a subjetividade dos oprimidos, evitando a psicologização das situações de injustiça (Fraser, 2007, p. 113-14). 
Ademais, para que a paridade de participação seja possível, há duas condições necessárias: 1 . a distribuição de recursos materiais deve se dar de forma a assegurar independência e voz dos participantes, que seria a condição objetiva; 2. a condição intersubjetiva, que requer que os padrões institucionalizados de valoração cultural expressem igual respeito a todos os participantes e assegurem igual oportunidade de estima social.

Ou seja, a primeira está ligada à justiça distributiva e a segunda à filosofia do reconhecimento. Dessa forma, "uma concepção ampla da justiça, orientada pela norma da paridade participativa, inclui tanto redistribuição quanto reconhecimento, sem reduzir um ao outro" (Fraser, 2007a, p. 119-20).

\section{CONCLUSÃO}

Como pontapé inicial deste artigo, partimos da noção de que a prostituição pode ser considerada uma das instituições que mais revela e expressa as relações de poder entre homens e mulheres (Paradis, 2018) e, por essa razão, é indispensável ao pensamento político, justamente por catalisar tão bem problemas e questões caros à política e ao pensamento social. Dentro desse amplo cenário, partimos dos argumentos de pensadores alinhados ao socialismo e ao marxismo, que se destacam por sua visão crítica acerca da prostituição, distanciando-se de moralismos de uma suposta pureza sexual, mas do contrário, que se alicerçam à analogia e à proximidade da prostituição com as opressões advindas do sistema capitalista, bem como da situação de subordinação em que se encontra o trabalhador, pautando também a situação das disparidades entre homens e mulheres nesse contexto. Suas contribuições foram preciosas para que a proposta abolicionista fosse concebida, em contraste às propostas proibicionistas e regulamentaristas, gerando mais uma possibilidade de se pensar a prostituição e suas problemáticas visando a emancipação das mulheres que estão ali inseridas (tanto cisgênero quanto transexuais).

Partimos também da pressuposição que as abordagens do socialismo e do marxismo clássicos têm suas limitações - como todo projeto teórico - e precisariam ser revistas, sobretudo ao pensarmos a contemporaneidade e, principalmente, por conta do enfraquecimento do debate crítico à prostituição nas últimas décadas. Tomamos a tarefa, então, de retomar esse debate no mesmo teor dos socialistas clássicos, mas unindo forças a teorias comprometidas com a emancipação das mulheres dentro dos contextos das sociedades democráticas contemporâneas, como a teoria crítica de Fraser nos convida a fazer. Trouxemos, então, Pateman para abrir esse debate, já que sua teoria do contrato sexual permite pensar a questão do patriarcado e da prostituição de forma associada. Mas Pateman também tem 
suas limitações, além do importantíssimo papel de sua obra, que necessitam de algum fortalecimento para pensar os contextos da realidade social contemporânea de uma forma menos abstrata: é o que diz Fraser ao criticar seu modelo de senhor/ súdita, que não serviria como um enquadramento adequado de análise das relações de poder contemporâneas, devido à sua complexidade e às suas diversas nuances. Encontramos, desta forma, na teoria da própria Fraser possíveis caminhos para seguir rumo a uma teoria que consiga captar a realidade social e política contemporânea, pautando a emancipação das mulheres e a justiça social, de modo que consigamos analisar e repensar a prostituição de um modo crítico. Isso porque pretendemos repensá-la concebendo diagnósticos e prognósticos acerca da realidade social, tal qual seria a tarefa das teorias consideradas críticas (Fraser, 1985).

Para Pateman, como vimos, a prostituição seria a mais clara expressão de que uma pessoa é uma propriedade que pode ser transacionada e a mais clara formada institucionalização da subordinação de um indivíduo a outro, ou seja, neste caso, de uma mulher a um homem (Pateman, 2020 [1988]). Isto é, a prostituição é uma das formas de contrato calcada por uma relação de subordinação - numa situação em que a livre-escolha não seria concebida em um contexto autêntico e genuíno, mas pautado pela escassez de opções (Biroli, 2013, p. 130). E o problema não seria voltado às mulheres que se prostituem (ainda que, à primeira vista, elas sejam os principais atores sociais nesse cenário), mas às razões pelas quais há a enorme demanda por parte dos homens (que também são atores sociais decisivos na manutenção da prática) para que seus corpos estejam à venda como mercadorias dentro da lógica capitalista - que é o que, segundo a autora, há de errado com a prostituição (Pateman, 1999, p. 63).

Segundo a ótica de Fraser acerca da redistribuição e do reconhecimento - mas sobretudo do reconhecimento -, haveria aí, uma potencial situação de injustiça. Fraser alega que a característica central da injustiça de gênero é a construção de normas que privilegiam a masculinidade, produzindo o sexismo cultural, desqualificando coisas codificadas como femininas. O que resulta em diversos danos sofridos pelas mulheres, dentre eles, a violência e a exploração sexual, que configuram injustiças de reconhecimento (Fraser, 2006, p. 234), e que características da prostituição, tal como descritas por Pateman, estariam incluídas, segundo nossa interpretação. Para Fraser, ainda, o gênero seria um modo bivalente de coletividade, em que injustiças de redistribuição e reconhecimento estão entrelaçadas, reforçadas por normas culturais sexistas e androcêntricas que são institucionalizadas por meio do Estado e da desvantagem econômica das mulheres, o que restringe sua participação de modo igualitário nas esferas públicas de tomada de decisão e 
formação da cultura: "o resultado é um círculo vicioso de subordinação cultural e econômica” (Fraser, 2006, p. 234).

Diante desse cenário de injustiças bivalentes, vimos também como Fraser distingue os remédios entre "afirmativos" e "transformativos". Os primeiros, voltados a corrigir os efeitos desiguais de arranjos sociais sem abalar a estrutura subjacente; e os segundos, voltados a corrigir os resultados desiguais pela transformação total das estruturas (Fraser, 2006, p. 237). Por exemplo, no quesito da redistribuição, os remédios afirmativos, diz Fraser, longe de abolir a divisão de classes per se, sustentam-na e moldam-na. Resulta-se na "marcação" da classe desprivilegiada como deficiente e necessitada, já que engendram a desvantagem de classe sem mexer nas estruturas. Desse modo, "uma abordagem voltada para compensar injustiças de distribuição pode acabar criando injustiças de reconhecimento" (Fraser, 2006, p. 238).

Tendo em vista que, desde as análises primordiais dos socialistas, a massa das mulheres na prostituição abarca mulheres em situação de vulnerabilidade socioeconômica, vê-se que o remédio de redistribuição afirmativo, tal qual apresentado por Fraser, apenas minaria seu status social e desembocaria em um déficit de reconhecimento, na medida em que se estigmatiza esse determinado grupo, reforçando a injustiça de gênero existente, sem que se transforme de fato a estrutura social subjacente. E falamos em status pois, segundo o modelo de Fraser, as injustiças são calcadas na estrutura e nas relações sociais institucionalizadas, e não na psicologia individual (Fraser, 2007, p. 113-14). Ou seja, ainda recapitulando Pateman, pensar na noção estrutural da prostituição, para além das concepções individuais, é de suma importância para construir uma crítica atenta às raízes do problema. Remédios transformativos acerca da redistribuição $e$ do reconhecimento, portanto, transformariam a estrutura cultural-valorativa subjacente, pensando nos danos intrínsecos à estrutura social e à subordinação institucionalizada, enxergando a prostituição em seu teor macroestrutural, buscando não a amenização de seus males, mas a abolição de suas causas.

Essa seria uma maneira possível de se ler a prostituição: partindo do diagnóstico de que ela seria uma situação de injustiça de gênero, já que representa a falta de paridade de participação entre homens e mulheres, por ser uma instituição generificada e pelo comprador estar sempre em um status social mais elevado do que quem vende seu corpo (Fraser, 1993; Pateman, 1999). É uma forma de injustiça bivalente, pois abarca injustiças de redistribuição e de reconhecimento, exigindo ambos os remédios para que haja paridade de participação. Nosso prognóstico, portanto, utilizando das categorias de Fraser, é pela busca por remédios transfor- 
mativos, críticos às raízes estruturais e institucionais da questão da prostituição, que procurem aboli-las para dar espaço a novas normas culturais-valorativas que visem a emancipação das mulheres e a justiça social de um modo geral, sempre pautando-se pelo critério da paridade de participação como justificativa.

Concluímos, então, que Pateman e Fraser são autoras que podem conversar entre si, apesar de alguns entraves que parecem impedi-las no início - a exemplo, o fato de Pateman não considerar a categoria de gênero e de Fraser não se apoiar fielmente na concepção de patriarcado ${ }^{7}$. Em nossa interpretação, as autoras podem se tornar aliadas ao dar continuidade à crítica socialista à instituição da prostituição, já que ambas têm projetos calcados numa teoria pós-marxiana. Ainda que suas divergências necessitem ser melhor alinhadas, vemos na análise do problema da prostituição um exercício teórico que as aproxima: Pateman é uma autora de saída, que primeiro suscitam tema da prostituição como objeto de análise e crítica, de forma direta; Fraser, por sua vez, apesar de não se debruçar diretamente no problema da prostituição (a não ser em seu artigo de 1993), é capaz de trazer novos alcances à crítica que Pateman reivindica, se "aplicarmos" sua teoria da justiça à concepção que Pateman tem da prostituição. Com as categorias de análise de Fraser, que acabamos de explicitar, podemos identificar com maior clareza os problemas inscritos na prostituição, em seu sentido estrutural e institucional.

Contudo, isso não significa dizer que o amplo debate acerca da prostituição se limita somente à dimensão estrutural de justiça. A questão da (in)justiça, pensando nos alcances de uma análise teórico-normativa e teórico-crítica, é somente um dos "braços" que podem ser destrinchados a partir da discussão da prostituição e dos problemas que envolvem a prática. Há múltiplas formas de analisar e acessar o assunto, que são igualmente necessárias e importantes. Nossa tentativa foi, dentro dos alcances de um artigo, explorar uma dentre tantas chaves capazes de se analisar a prostituição: a chave da justiça, que entendemos como uma das principais preocupações do pensamento político (Fraser, 2014), mas que, ainda hoje, pouco é explorada ao pensarmos questões do feminismo que pouco adentram os debates da teoria política brasileira (Biroli, 2017), como é o caso da prostituição. Não tentamos, portanto, "fechar" conclusões acerca do tema, mas, ao contrário, tentamos contribuir com a "abertura" de um debate que ainda há de crescer dentro da teoria política. Mais do que procurar respostas, portanto, procuramos suscitar mais perguntas e inquietações acerca do tema, ampliando as gamas de análise

7 Fraser, em alguns textos, chega a citar o termo, mas não se debruça nele como ponto chave de sua argumentação, além de citá-lo entre aspas e alegar que, na contemporaneidade democrática, as mulheres não vivem sob regimes propriamente patriarcais (i.e. Fraser, 1993; 2007; 2009). 
da teoria normativa, que não se limitam a uma abstração apenas "ideal” (Melo, 2017), todavia que tenham potencialidades de análise capazes de corroborar com a pesquisa social.

\section{REFERÊNCIAS BIBLIOGRÁFICAS}

AFONSO, Mariana (2014). Regulamentar para quê(m)? As representações sociais de prostitutas sobre a regulamentação da "profissão". Dissertação (Mestrado em Psicologia). São Carlos: Universidade Federal de São Carlos.

BIROLI, Flávia (2013). Democracia e tolerância à subordinação: livre-escolha e consentimento na teoria política feminista. Revista de Soc. e Política, v. 21, n. 48, p. 127-142.

BIROLI, Flávia (2017). Teorias feministas da política, empiria e normatividade. Lua Nova, São Paulo, v. 102, p. 173-210.

BONOMI, Carolina (2019). "Mulher da Vida, É Preciso Falar": um estudo do movimento organizado de trabalhadoras sexuais. Dissertação (Mestrado em Ciência Política). Campinas: Universidade Estadual de Campinas.

BROWN, Wendy (1987). Where is the Sex in Political Theory? Women \& Politics, v. 7, n. 1, p. 3-23.

FRASER, Nancy (1993). Beyond the Master/Subject Model: Reflections on Carole Pateman's Sexual Contract. Social Text, n. 37, p. 173-181.

FRASER, Nancy (2006). Da redistribuição ao reconhecimento? Dilemas da justiça numa era “pós-socialista. Cadernos de campo, São Paulo, n. 14/15, p. 231-239.

FRASER, Nancy (2007a). Mapeando a imaginação feminista: da redistribuição ao reconhecimento e à representação. Estudos Feministas, Florianópolis, v. 15, n. 2, p. 291-308.

FRASER, Nancy (2007b). Reconhecimento sem ética? Lua Nova, São Paulo, v. 70, p. 101-138.

FRASER, Nancy (2009). O Feminismo, o capitalismo e a astúcia da história. Mediações, Londrina, v. 14, n.2, p. 11-33.

FRASER, Nancy (2014). Sobre justiça: lições de Platão, Rawls e Ishiguro. Revista Brasileira de Ciência Política, n. 15, p. 265-277.

FRASER, Nancy (1985). What's critical about critical theory? The case of Habermas and gender. New German Critique, n. 35, p. 97-131.

HIRATA, Helena et al (2009). Dicionário Crítico do Feminismo. São Paulo: Unesp.

KEMPADOO, Kamala (2001). Women of Color and the Global Sex Trade: Transnational Feminist Perspectives. Meridians, v. 1, p. 28-51.

KOLLONTAI, Alexandra (2007). A nova mulher e a moral sexual. São Paulo: Expressão Popular.

NICHOLSON, Linda (1994). Interpreting gender. Signs, v. 20, n. 1, p. 79-105. 
NUSSBAUM, Nussbaum, Martha (1998). “Whether from Reason or Prejudice”: Taking money for bodily services. The Journal of Legal Studies, v. 27, n. S2, p. 693-723.

MELO, Rúrion (2017). Teoria política e pesquisa social. Lua Nova, São Paulo, v. 102, p. 211-230.

MIGUEL, Luis F (2017). Carole Pateman e a Crítica Feminista do Contrato. Rev. Brasileira de Ciências Sociais, v. 32, n. 93, p. 1-17.

OVERALL, Christine (1992). What's Wrong with Prostitution? Evaluating Sex Work. Signs, v. 17 , n. 4 , p. $705-724$.

PARADIS, Clarisse Goulart (2018). A prostituição no marxismo clássico: crítica ao capitalismo e à dupla moral burguesa. Rev. Estudos Feministas, Florianópolis, v. 3, n. 26 , p. $1-20$.

PARADIS, Clarisse Goulart (2017). Feminismo, liberdade e prostituição: para além do dissenso democrático. Tese (Doutorado em Ciência Política). Minas Gerais: Universidade Federal de Minas Gerais.

PATEMAN, Carole 2020 [1988]. Contrato Sexual. São Paulo: Paz e Terra.

PATEMAN, Carole 1992 [1970]. Participação e teoria democrática. São Paulo: Paz e Terra.

PATEMAN, Carole 1985 [1979]. The problem of political obligation: a critique of liberal theory. Berkeley: University of California Press.

PATEMAN, Carole (1999). What's Wrong with Prostitution? Women's Studies Quarterly, v. 27, n. $1 / 2$, p. $53-64$

PISCITELLI, Adriana (2012). Feminismos e Prostituição no Brasil: Uma Leitura a Partir da Antropologia Feminista. Cuadernos de Antropología Social, n. 36, p. 11-31.

RAGO, Margareth (1990). Os prazeres da noite: prostituição e códigos da sexualidade feminina em São Paulo (1890-1930). Tese (Doutorado em História Social). Campinas: Universidade Estadual de Campinas.

TRISTAN, Flora (2009). Paseos en Londres. Lima: Biblioteca Nacional del Perú, Biblioteca Digital Andina.

SHOWNDEN, Carisa (2016). "Feminist Sex Wars”. In: NAPLES, Nancy A. (org.).The Wiley Blackwell Encyclopedia of Gender and Sexuality Studies, Nancy A. Naples (ed.), p. 1-3. SHRAGE, Laurie (2016). "Feminist Perspectives on Sex Markets". In: ZALTA, Edward N. (org.). The Stanford Encyclopedia of Philosophy (Fall 2016 Edition). Disponível em: $<$ https://plato.stanford.edu/archives/fall2016/entries/feminist-sex-markets/>. Acesso em: 18 de ago. de 2021.

WALKOWITZ, Judith (1980). The Politics of Prostitution. Signs, v. 6, n1. p. 123-135.

Recebido: 10/04/2021 | Aprovado: 15/08/2021 